CuPAUAM. 17-1990, 25-33

\title{
APROXIMACION A LA ARTESANIA DEL MUEBLE IBÉRICO: ALGUNAS PRECISIONES SOBRE EL TRONO DE LA DAMA DE BAZA (GRANADA)
}

\author{
ENCARNACION RUANO RUIZ. \\ Asociacion EsPaÑola de AMigos de LA \\ ARQUEOLOGLA
}

\section{Resumen}

La escultura sedente de Baza (Granada), nos ha permitido el estudio del trono, sin duda un mueble existente en la época.

Presentamos un hipotético desarrollo constructivo a través del análisis de sus estructuras, que nos llevan a valorar la existencia de ebanistas en un momento temprano de la cultura ibérica.

\section{Summary}

The Iberian seated sculpture called "Dama de Baza" (Granada) offers the oportunity to analyse the construction of her throne, no doubt an existing piece of furniture in her time.

We present an hypothetical reconstruction through the analysis of its structure, which makes evident the presence of skilled cabinetmakers at an early moment of Iberian Culture.

Uno de los oficios menos conocido del mundo ibérico es el de la artesanía del mueble.

Tanto las fuentes como la bibliografía tradicional y moderna, son muy parcas en documentar el trabajo de la madera y la descripción y fabricación del mueble ibérico.

La gran cantidad de datos que ofrecen los restos arqueológicos sobre esta actividad artesanal, nos ha inducido a realizar una monografía, (en curso de publicación) donde se ha tratado de reconstruir aspectos materiales y técnicos, y donde se documentan la gran variedad de muebles usados por diferentes estamentos de la sociedad ibérica.

En este artículo tratamos de acercarnos al trono de la Dama de Baza, uno de los más conocidos del mundo ibérico. Sin lugar a dudas es la representación escultórica de un trono que existía en la época y que sirvió de modelo al artista autor del conjunto pétreo.

La contemplación directa en las salas de escultura ibérica del Museo Arqueológico Nacional, sugiere algunas precisiones. 
El doctor Presedo dedicó al "trono o sillón" de Baza, dos extensos párrafos. En uno describe el mueble de manera general, y en otro se documentan los paralelos con el mundo griego: "ElTrono o sillón. La figura se asienta sobre un trono muy característico tallado en el mismo bloque. Indudablemente representa un sillón de madera, que el artista ha reproducido con toda fidelidad. Es el clásico trono de cuatro patas verticales, bracero y respaldo. Las patas están representadas con cierto detalle en las molduras. Las delanteras arrancan del asiento como un bloque que se va estrechando hacia abajo, donde tiene una moldura, y terminarán en unas garras, detalle de gran importancia para su clasificación arqueológica. Estas garras tienen las uñas perfectamente dibujadas. Las patas traseras son similares, pero sin el remate de la garra. Encontramos rota la terminación de la pata trasera izquierda, que, por cierto, se perdió en el transporte de la estatua de Baza a Madrid, habiendo sido entregada al señor Navarrete en el propio yacimiento por el que suscribe. Actualmente falta a la estatua restaurada en el Museo Arqueológico Nacional. Está perfectamente dibujado el travesaño entre la pata anterior y posterior de cada lado. Los brazos sobresalen ligeramente. El saliente del derecho se había roto hacía mucho y fue hallado en el suelo. Se ha podido pegar de nuevo. El sillón lleva dos alas como prolongación del respaldo que se encontraron en posición primitiva pero desprendidas. Si se mira la escultura por atrás, se ve cómo fueron concebidas por el artista como una prolongación del respaldo es decir, como una tabla clavada sobre el asiento, haciendo incluso notar el resalte típico. Estas alas tienen forma alabeada. Todo el sillón va pintado de marrón oscuro, incluido la franja exterior de las alas.

Sin embargo, en éstas hay una franja interior blanca, la cual, en nuestra opinión, hay que interpretar como la representación de madera más blanca, quizá de madera más fina. La identificación como la representación de madera puede demostrarse observando cómo en algún trozo se intenta pintar los nudos cortados al trabajar la madera". (Presedo, 1982, 214)

"El Trono. El trono sobre el que se asienta la Dama tiene paralelos claros en la historia del arte griego. Dentro de la tipología elaborada por Gisela Richter puede incluirse en la serie de tronos con patas de animal. Esta forma deriva de prototipos egipcios, y en Grecia los encontramos desde el siglo VI hasta la primera mitad del siglo V a. C. . Después de esta fecha van cayendo en deshuso y aparece solo ocasionalmente en monumentos con relaciones orientales. Su área de expansión tiene un punto importante, en Sicilia, de donde creemos fué tomado, así como el tipo general de la Dama de Baza. (Presedo, 1982, 139).

Hasta aquí los datos conocidos sobre el trono ibérico de Baza.

Ante la gran cantidad y variedad de muebles usados por la sociedad ibérica, conviene puntualizar la clase de asiento usado por la Dama de Baza. ¿Era un simple sillón o un trono?. Sin ninguna clase de duda se trata de un trono, Siége d'honneur (Daremberg y Saglio, vol V, 278), mueble usado sólo por personajes pertenecientes a estamentos privilegiados de la sociedad o dioses, como reflejan las fuentes.

La Biblia en el Libro Primero de los Reyes (X, 18), describe el trono de Salomón :"Hizo asimismo el rey Salomón un trono grande de marfil y lo guarneció de oro purísimo amarillo. Tenía el trono seis gradas y lo alto del trono por el respaldo era redondo y por uno y otro lado salían dos brazos o apoyos que sostenían el asiento y junto a cada uno de estos brazos había leones".

Daniel, V, 20, habla del trono de Nabucodonosor;en los Hebreos I, 8, se alude al trono de Dios. En otros pasajes bíblicos se habla de los tronos simbólicos:Job, XXXVI, 7;Lucas, XXII, 30;Apocalipsis IV, 4 y Proverbios, XX, 20.

En diversos pasajes de la Odisea se alude al trono de los dioses (rapsodias I, VII, XIX, XX, XXI, XXIII). En el pasaje I, donde Telémaco diferencia bien el mueble en el que debe sentar una diosa (Minerva) "acercándose para (Telémaco) sí una labrada silla". 
Homero en la rapsodia XIX dice. "Colocáronle junto al hogar el torneado sillón con adornos de marfil y plata; el cual había sido fabricado por el artífice Icmalio, que le puso un escabel para los pies, adherido al mismo y cubierto con una grande piel (Segolá, 198). Aquí el traductor habla de sillón, aunque nosotros entendemos que el autor se refiere "a un trono".

Es importante en este pasaje el hecho de mencionar al artesano que realizó el "torneado sillón", prueba de la categoría de que gozaba este oficio en el mundo homérico. En el mismo pasaje XI, se repite por dos veces el "aúreo trono" como asiento de la divinidad Aurora.

Pausanias (V-II, 2), describe el trono de Zeus realizado por Fidias en Olimpia:"estaba adornado con oro y piedras preciosas, tambien con ébano y hierro y tenía figuras pintadas e imágenes forjadas en él”.

El trono de Asklepios en Epidauro, tenía añadidos los héroes argivos realizados en relieve. (Pausanias II, 27, 2). El trono de Apolo en Amiclea realizado por Bathykles de Magnesía, estaba también laboriosamente decorado (Pausanias III, 18, 9). En este caso se menciona el nombre del artesano como en el pasaje XIX de la Odisea. Insistimos en considerar como trono el asiento de la Dama de Baza, personaje de gran categoría, visible en el atuendo, en la riqueza de las joyas y en el "gesto" de su posición sedente, con la mano derecha apoyada en la rodilla del mismo lado y la izquierda cerrada aprisionando un ave. La representación de un escabel, en este caso un almohadón, contribuye a definir el mueble como un trono.

I. - Descripción. La realidad con que el escultor representó el mueble y el tamaño casi real, nos permite establecer las medidas hasta ahora inéditas. $\left({ }^{*}\right)$

Las dimensiones generales son: altura total, 75, $4 \mathrm{~cm}$. ;largo de las alas, $103 \mathrm{~cm}$. ;ancho de las alas, $33,7 \mathrm{~cm}$. ;altura de las patas $41,2 \mathrm{~cm}$. ;brazos, $30,6 \mathrm{~cm}$.

En las medidas del mueble se aprecian pequeñas oscilaciones que alteran levemente su simetría.

II. - Análisis de la estructura. El mueble es de tipo cúbico y muy macizo. El trono está realizado mediante una armadura formada: a) brazos; b) asiento; c) patas; d) falso respaldo y e) un respaldo de alas. (Fig. 1).

Existe un travesaño intermedio sólo en el lado derecho, (que delimita el orificio de la urna) y une la pata anterior derecha a la pata exterior del mismo lado.

a) Los brazos son muy gruesos $(6,6 \mathrm{~cm}$. de lado) y tiene $30,6 \mathrm{~cm}$. de largo.

b)El asiento solo se aprecia en la escultura frontalmente en la esquina del lado izquierdo, y permite situarlo como se recoge en el dibujo de perfil (Fig. 1 - 2).

c) Las patas delanteras son rectas y miden de altura $41,2 \mathrm{~cm}$.

Son más gruesas en la parte que se unen al bracero $(8,9 \mathrm{~cm}$.), disminuyen de tamaño hasta llegar a los $3 \mathrm{~cm}$., a esta altura el artesano hizo una moldura cuadrángular de $2 \mathrm{~cm}$. de lado y acabó el tramo con unos pies esculturados con garras de felino, de uñas bien diferenciadas, que miden en la base 10, $4 \mathrm{~cm}$., punto de apoyo del mueble.

Las patas traseras tienen la misma disposición que las delanteras si exceptuamos que falta la mitad de la moldura externa y los pies figuardos.

d) falso respaldo, contribuye a sustentar el respaldo con alas.

e)El respaldo de gran tamaño, $103 \mathrm{~cm}$. de largo y $33,7 \mathrm{~cm}$. de ancho, se apoya sobre el "falso respaldo".

(*) Hemos de hacer constar nuestro agradecimiento a Dña Alicia Rodero, conservadora del MAN, que nos ha facilitado el acceso a la escultura, y a Dña María Sanz que ha tomado las medidas. 


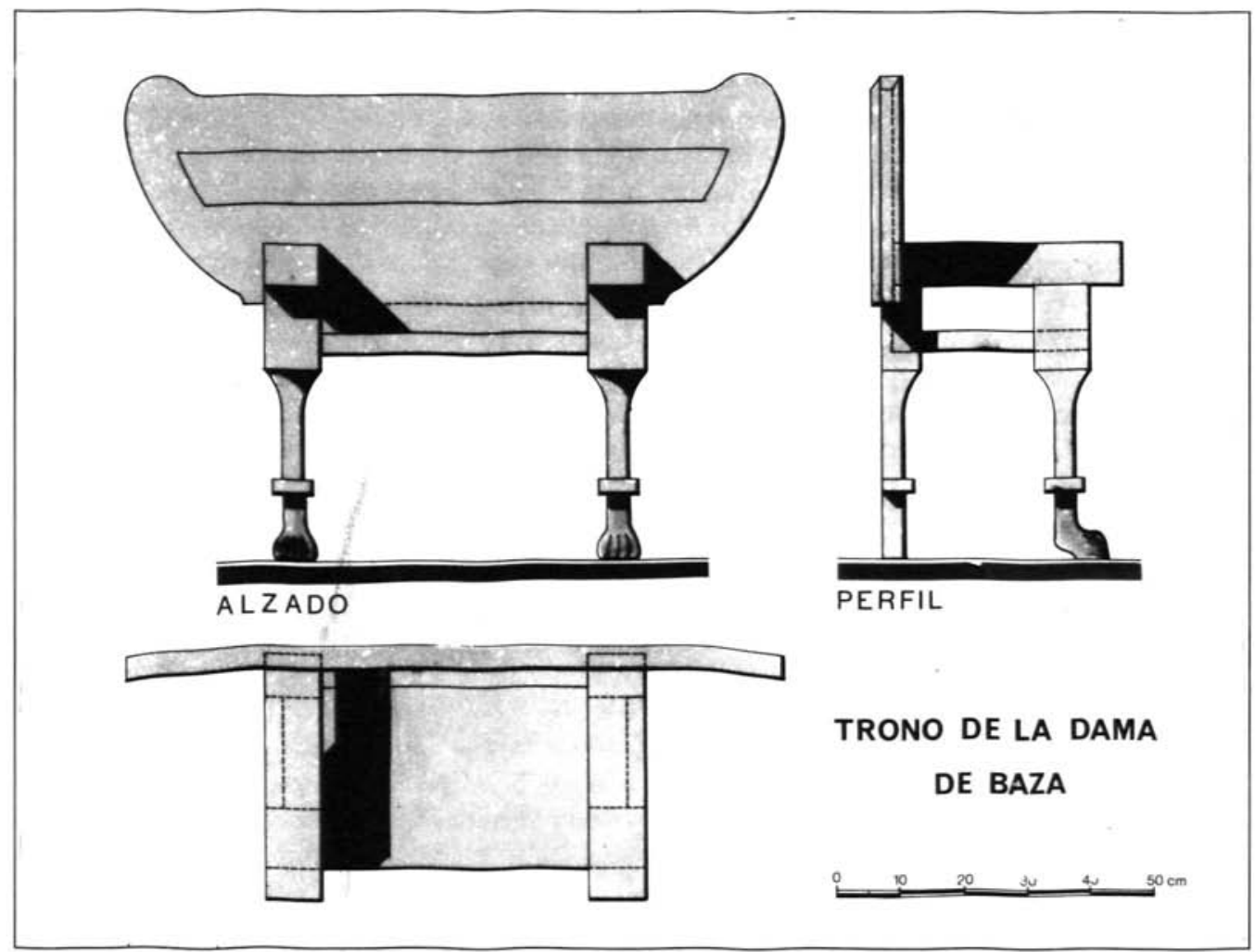

Figura 1. Trono de la Dama de Baza. 1. - Alzado, 2. - Perfíl.

Existe un almohadón, a manera de escabel que mide de ancho mínimo $28,8 \mathrm{~cm}$. y máximo de $29,3 \mathrm{~cm}$. . La altura máxima de este elemento es de 5, $4 \mathrm{~cm}$. y la mínima de 4, $8 \mathrm{~cm}$. El uso del almohadón era muy frecuente en el mundo griego como complemento de la decoración.

III. - Paralelos. Consideramos como partes definidoras del estilo del mueble: el respaldo con alas y las patas esculturadas.

El respaldo con alas más o menos desarrolladas fué muy frecuente en los sillones de damas sedentes representadas en numerosas terracotas de ámbito meditteráneo. Valgan algunos ejemplos como los procedentes del Atica (Fig. 2-2), Beocia, Rodas, Eleonte de Tracia, Costa Jónica, Magna Grecia y Sicilia (fig. 2-1) (Mollard Besques, n 67, 83, al 87, 205, 206, 326, 526 al 530, $536,537,559,560)$.

Todas estas terracotas están fechadas a finales del siglo V a. C.

En Ibiza existen tres terracotas, una masculina y dos femeninas, (Almagro, 1980, láms. 87 y 89) que se sientan en tronos con alas. Los sillones con patas de animales tienen su origen, como ya advirtió Presedo, en Egipto. Decoran muchos muebles de Asiria y Persia y están muy representados en la plástica griega desde fines del siglo VI hasta la primera mitad del V a. C. .

Sillones con patas de animales se observan en el trono de Tutankamon (XVIII Dinastía) realizado en madera (fig. 3-1), o en un escabel procedente de Ugarit (fig. 3-2), en tronos procedentes de Arcadia (fig. 3-3), Laconia (Atenas) (fig. 3-4), de Siracusa (fig. 3- 5), Locri (Richter, 1926 


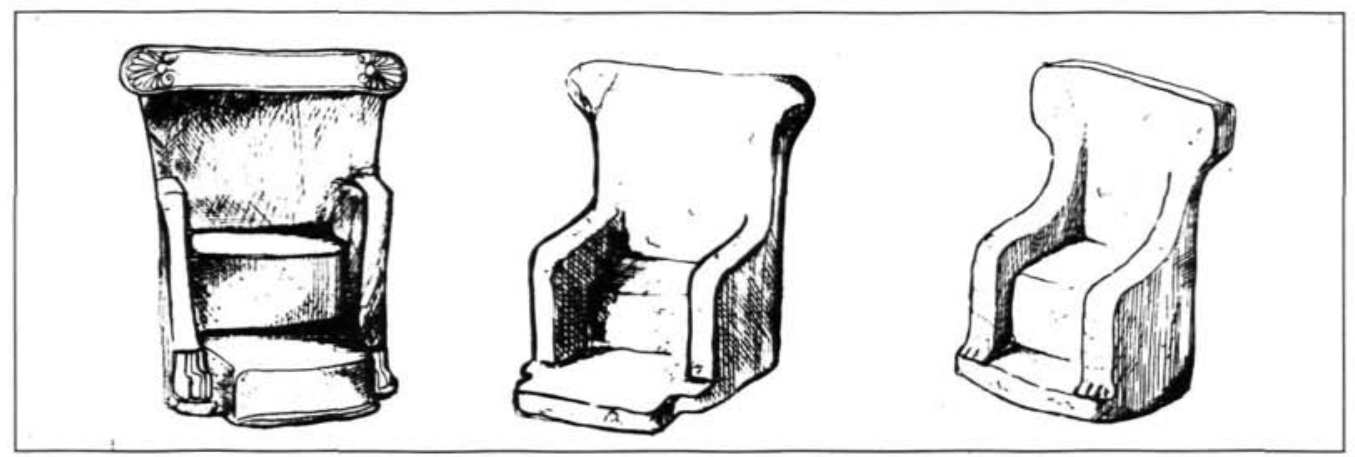

Figura 2. Tronos representados en terracotas procedentes de 1. - Beocia, 2. - Atica, 3. - Ibiza.

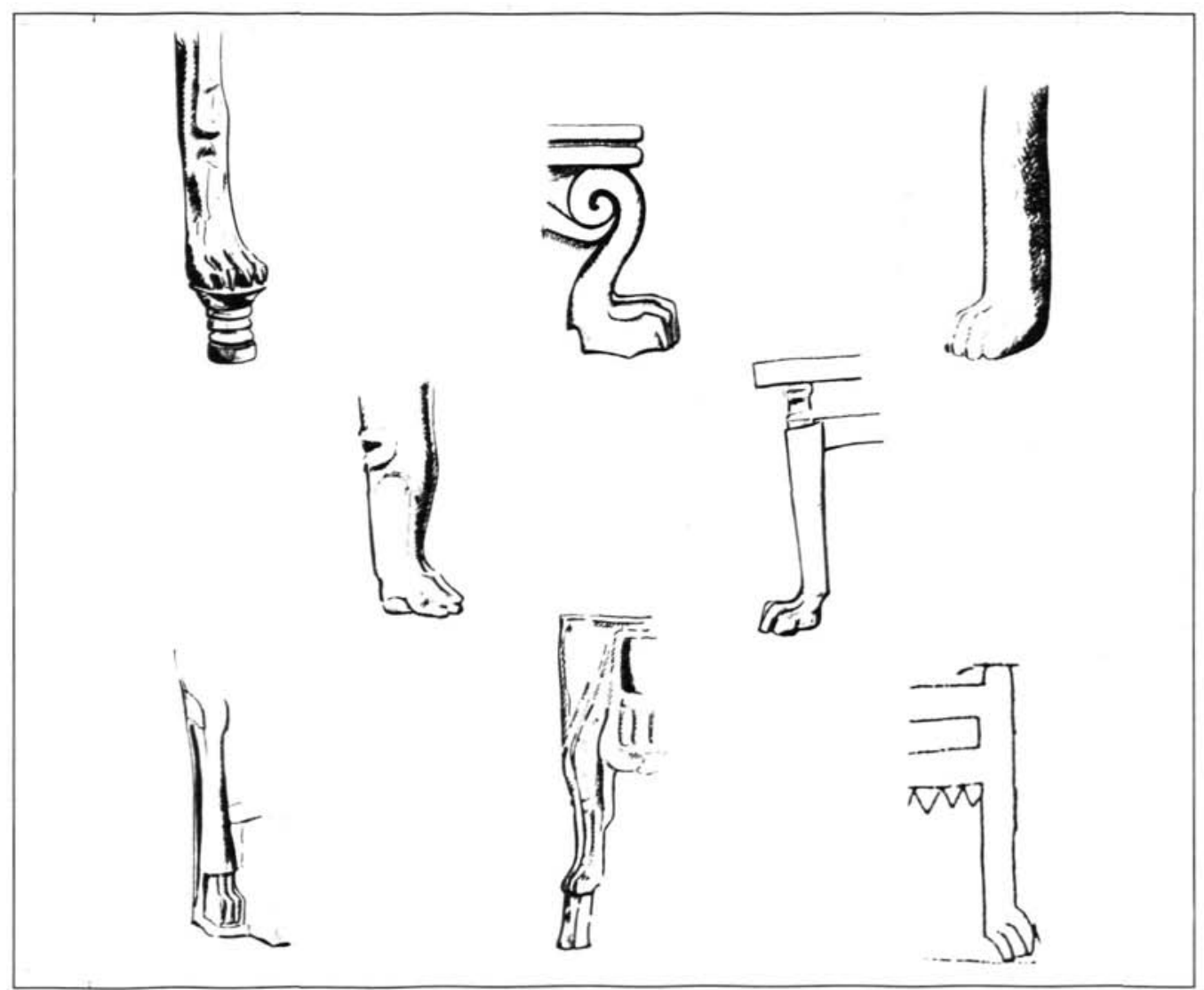

Figura 3. Diversas interpretaciones de tronos con las patas acabadas en garras de animales:1. - Tutankamon. 2. - Ugarit (escabel), 3. - Arcadia, 4. -Laconia, 5. - Siracusa, 6. -Locri, 7, . Ras Shamra, 8. -Pozo Moro (Chinchilla, Albacete). 
y 1966). (fig. 3-6), de Ibiza (San Nicolás, 1983, 19), en una estela procedente de Ras Shamra (Siria) (fig. 3-7), y de Pozo Moro, Chinchilla, Albacete (Almagro Gorbea, 1980) (fig. 3-8).

Hemos de hacer constar que, a pesar de las numerosas representaciones de muebles en terracotas en el mundo mediterráneo, el trono de Baza acusa la personalidad del artesano ibérico que supo mezclar con su propio estilo una moda llegada a la península. Respaldos con alas y patas esculpidas solo aparecen en una terracota púnica procedente de Ibiza (San Nicolás, 1983, 18) (Fig. 2-3) y en dos terracotas sicilianas, antes mencionadas, aunque en este caso las alas se limitan a unas pequeñas palmetas que sobresalen en el respaldo del mueble, (Ufford, 1941, fig. 44), (fig. 2 - 1)

IV. - Hipótesis sobre la técnica de fabricación. El artesano ebanista (que supuestamente habría realizado un mueble de parecidas características al que copió el escultor) debió partir de un diseño que a tenor de los paralelos mencionados debía de estar de moda entre las personas acomodadas del mundo mediterráneo, adaptándolo a su propia interpretación.

La ejecución de este diseño sugiere conocimientos de dibujo, geometría y de elementos como reglas, compases, etc., bien documentados por los hallazgos (Pla Ballester, 1968- 1969).

La elección de los materiales, en este caso solamente madera, sería el siguiente paso. Era fundamental elegir bien la materia adecuada para su buen manipulado, de ello dependía en parte la estabilidad y duración del mueble.

Sabemos la utilización en época antigua de maderas de boj, olivo y tilo (Hundt, 1968, 203), con propiedades excelentes para ser talladas. En el Amarejo, Bonete (Albacete) se han estudiado todos los restos de madera tanto de productos manufacturados como de restos de ramas y vigas, documentandose pino negral, encina, cerezo silvestre, chopo, madroño, fresno, alcornoque, enebro o sabina, clemátide y boj, además de vid o parra.... (Broncano, 1989, 44). La tumba no 17 de la Joya tenía restos de nogal (Garrido y Orta, 1978, 63- 67). No se conoce con precisión la madera usada en los muebles de taracea de Zalamea de la Serena. Según Maluquer, "dá la impresión como si la madera de encina constituye con la de pino la mayoría de los carbones..."(Maluquer, 1983, 98).

Si nos apoyamos en la coloración de la escultura dá la impresión el uso de dos especies arbóreas; una de ellas, la más clara, podría ser de tilo.

El aserrado y preparación de las piezas del trono, requería la existencia de un taller con un mínimo de infraestructura donde se cortaran los tablones con las medidas oportunas. La talla de los elementos sustentantes demuestra la pericia en el manejo de las herramientas. Este hecho está constatado por los hallazgos arqueológicos de útiles metálicos de carpintero en el país valenciano, (Pla Ballester, 1968 - 1969), en Numancia, (Manrique, 1980, 68-154) y Ciudad Real, (Aurrecoechea, et alii, 1987, 272), etc.

La decoración de las patas del trono de Baza delata el conocimiento de la talla de la madera, arte complicado que requiere experiencia (Upton, 1984, 24) como la del "tallista" de Cancho Roano, (Maluquer, 1983, 100).

Las formas rígidas del trono de la Dama de Baza, requieren ensambladuras hechas a caja y espiga, como la mayoría de los muebles egipcios conservados (Schmitz, 1952, 12).

Preparados ya todos los elementos y a la vista del diseño se comenzaría la organización de las piezas que conforman el mueble. La unión y enlace de las distintas partes de madera se hacía, y aún se hace, por medio de cortes adecuados en unos y otros elementos para obtener su perfecta correspondencia y ajuste.

Nos hemos permitido presentar de una manera hipotética el despiece constructivo del trono de la Dama de Baza. 
Los elementos que componen el mueble ya descrito con anterioridad, exigen una construción cúbica con ensamblajes a caja y espiga según el siguiente esquema (fig. 4): 1) Las cuatro patas macizas se unirían de dos en dos mediante los brazos. 2) Las cuatro patas quedarían a su vez fijadas mediante el asiento. 3) Un falso respaldo retranqueado en (perfil), daría consistencia

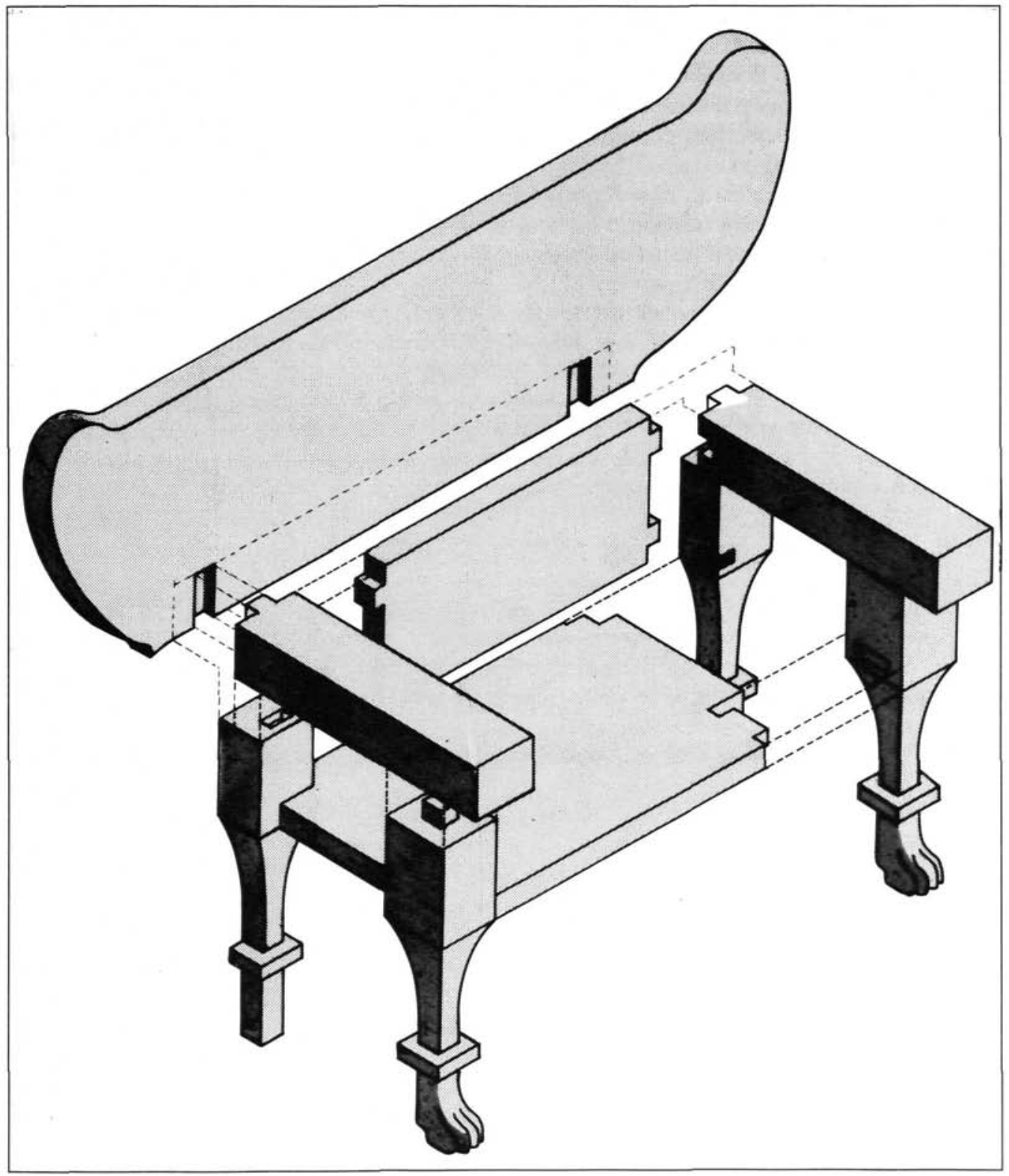

Figura 4. Trono de la dama de Baza. Despiece constructivo. 
a la armadura y serviría de unión a patas, brazos y asientos. 4) Sobre el falso respaldo apoyado y ensamblado en los brazos se situaría el respaldo con alas. 5)El travesaño solo situado en el lado derecho de la escultura contribuiría a dar mas estabilidad al trono (no se ha representado en el dibujo).

La unión de todos estos elementos estaría consolidada mediante el uso de pegamento, a base de resina, atestiguada en los restos de muebles de Cancho Roano (Maluquer, 1983, 100).

$V$. - Conclusiones. El mueble en el que se asienta la Dama de Baza es un trono. Permite diferenciarlo de los sillones por la categoría del personaje representado.

El realismo de la escultura permite un estudio analítico de las estructuras del mueble, compuesto por una armadura a base de bracero, con patas, un solo travesaño (sólo visible en el lado derecho del mueble), asiento, "falso respaldo" y respaldo de alas.

La ejecución de las diversas partes del mueble sugiere: amplios conocimientos en la elección de la madera;diseño;manejo de herramientas apropiadas;conocimiento técnico de la talla, embutido y construcción (ensamblaje).

Todo ello nos hace suponer la existencia de un taller de carpintería en los albores del siglo IV, situado en el sur de la península, especializado en la ejecución de muebles para un estamento privilegiado de la sociedad ibérica. 


\section{BIBLIOGRAFIA}

Almagro Gorbea, M., 1983: "Pozo Moro, un monumento funerario orientalizante" MM, 24, 177-293, Heidelberg.

AlmaGro Gorbea, Ma J. 1980: “Corpus de las terracotas de Ibiza”, BHP, XVIII, Madrid.

... 1983 : "Pozo Moro, un monumento funerario orientalizante”, $M M, 24,177-293$, Heidelberg.

AURRECOECHEA, J et alii, 1987: "Mobiliario metálico del yacimiento íbero-romano de La Bienvenida, en la provincia de Ciudad Real”, Oretum, II, 249 -292, Ciudad Real.

Biblia 1981 :Traducción de los textos originales por el equipo hispano-americano de la Casa de la Biblia, 10 ed., Madrid.

Broncano S. 1989: "El deposito votivo ibérico de El Amarejo, Bonete, Albacete”, EAE, 156, Madrid.

DAREMBERG SAGLIO : Dictionnaire des antiquités gecques et romaines d'aprés les monuments, vol. V, París.

GarRidO, J. P; OrTa, H. 1978: "Excavaciones en la necrópolis de la Joya, Huelva”, EAE, 96, Madrid.

HOMERO Odisea. Versión directa y literal del griego por Luis Segolá y Estalella, Madrid.

HundT, H. J. 1968: "Die Verkohlten Reste von Geweben, Geflechtem seilen, Schüren und Holegeraten aus grab 200 von El Cigarralejo ", $M M$, 9, Heidelberg.

MALUQUER DE MORTES, J. 1983: El santuario protohistórico de Zalamea la Serena (Badajoz), Barcelona

MANRIQUE, Ma 1980 : Instrumentos de hierro de Numancia, Madrid.

MOLLARD-BESQUES, S. 1954: Catalogue raisonné des figurines et reliefs en terre-cuite grecs, etrusques et romains, I, Epoques préhellenique, géométrique, archáique et classique, Paris.

Pla Ballester, E. 1968: "Instrumentos de trabajo ibéricos en la región valenciana”, Estudios de Economía antigua de la Peninsula Ibérica, 143-190, Barcelona.

PAUSANIAS Description of Greece, (With an English tranlation by WHS Jones), Libro I-II -1978, III-IV1977.

Presedo Velo, F. 1982: "La necrópolis de Baza”, $A E A, 119$, Madrid.

RiCHTER, G. M. 1926: Ancient furniture, A History of Greek, Etrucan and Roman furniture, Oxford.

... 1966: The furniture of the greeks, etruscan and romans, London.

SAN NiCOLAS, M. P. 1983: "La indumentaria púnica representada en las terracotas de ibiza", AEspA, LVI, 15 - 46, Madrid.

SCHмrTZ, H. 1952: Historia del mueble. Estilos del mueble desde la antigüedad hasta mediados del siglo XIX, Barcelona. 